NASA

Technical Memorandum 100115

AIAA-87-1745

AVSCOM

Technical Report 87-C-21

\title{
Performance of Two 10-lb/sec Centrifugal Compressors With Different Blade and Shroud Thicknesses Operating Over a Range of Reynolds Numbers
}

Gary J. Skoch

Propulsion Directorate

U.S. Army Aviation Research and Technology Activity-AVSCOM Lewis Research Center

Cleveland, Ohio

and

Royce D. Moore

Lewis Research Center

Cleveland, Ohio

Prepared for the

23rd Joint Propulsion Conference

cosponsored by the AIAA, SAE, ASME, and ASEE

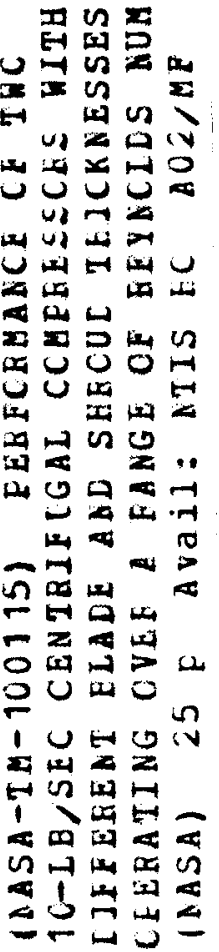

San Diego, California, June 29-July 2, 1987

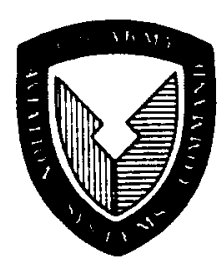


PERFORMANCE OF TWO 10-LB/SEC CENTRIFUGAL COMPRESSORS WITH OIFFERENT

\author{
BLADE AND SHROUD THICKNESSES OPERATING OVER A \\ RANGE OF REYNOLDS NUMBERS \\ Gary J. Skoch \\ Propulsion Directorate \\ U.S. Army Aviation Research and Technology Activity - AVSCOM \\ Lewis Research Center \\ Cleveland, Ohio 44135 \\ and \\ Royce D. Moore \\ National Aeronautics and Space Administration \\ Lewis Research Center \\ Cleveland, Ohio 44135
}

\title{
SUMMARY
}

A $10-1 \mathrm{~b} / \mathrm{sec}, 8: 1$ pressure ratio, centrifugal compressor was tested at the NASA Lewis Research Center as part of a program to study the effect of scaling centrifugal compressors to small sizes. It was scaled down to $2 \mathrm{lb} / \mathrm{sec}$ where adjustments were made to increase the blade thickness and fillet radii. The adjustments were required because of structural and manufacturing considerations. To determine the effect of the modifications, the $2-1 \mathrm{~b} / \mathrm{sec}$ design was directly scaled back up to $10 \mathrm{lb} / \mathrm{sec}$ and a second compressor with thicker rator blades and diffuser vanes was built. Both $10-1 \mathrm{~b} / \mathrm{sec}$ compressors were tested over a range of speed, mass flow, Reynoids number, and tip clearance. Impeller shrouds with two different wall thicknesses were tested to determine the effect on performance of heat transfer from the compressor exit to inlet.

Test results at design speed, with the design tip clearance of 0.009 in., showed that the thin compressor produced a pressure ratio of 7.69 , with a total to total adiabatic efficiency of 0.792 at the design mass flow of $101 \mathrm{~b} / \mathrm{sec}$. At the same mass flow and operating condition, the thick compressor produced a pressure ratio of 7.64 with an efficiency of 0.777 .

The efficiency loss that occurred as Reynolds number was reduced was found to be dependent on the thickness of the shroud that was used. The exponent commoniy used in a relation between loss and Reynolds number was found to be equal to -0.095 for both compressors when tested with the thin shroud, and -0.183 when the thick shroud was used.

The tip clearance of the thin compressor was increased in 0.001 in. increments at design speed with an inlet total pressure of 14 psia. The efficiency was found to decrease about 0.25 points for every 1 percent of blade height increase in tip clearance.

This paper is declared a work of the U.S. Government and is not subject in copyright protection in the United Siates. 


\section{INTROOUCTION}

Centrifugal compressors provide several performance advantages when used in small gas turbine engines. Among them is the high pressure ratio that can be achieved in a single stage which allows fewer stages to be used in an engine. Centrifugal compressors are also more rugged than small axial compres. sors and tend to maintain their efficiency better than equivalent axial com. pressors as flow size is reduced.

Theoretically, for directly scaled compressors of both the axial and centrifugal type, one would expect that the only increase in loss to occur as flow size is reduced would be associated with the lower Reynolds numbers at which the compressor operates; considering standard day inlet conditions as a reference. However, direct scaling to very small sizes is often not possible due to structural considerations and the increased difficulty of manufacture. Because of the inability to directly scale all design parameters, additional losses do result over and above the viscous loss correlated by Reynolds number. It is known that the factors which contribute to additional losses include increased blade and shroud thickness, rougher surfaces in a relative sense, larger fillet radii, etc. But the change in loss caused by individual varia. tions in these parameters is not well known.

The effect of scaling axial compressors to smaller sizes has been well documented, an example of which is given in a study reported by wiggins and waltz (ref. 1). A 54-1b/sec, eight-stage axial compressor, was directly scaled (scale factor $=0.304$ ) down to a flow size of $5 \mathrm{lb} / \mathrm{sec}$. The authors were very careful to ensure that a 11 design parameters were directly scaled. Subsequent testing of the scaled compressor showed that the direct scaling of all param eters resulted in no performance loss, other than that which can be attributed to Reynolds number. Other examples of axial compressor scaling can be found in references 2 and 3 .

Based on the lack of similar data for centrifugal compressors, and our present inability to calculate centrifugal compressor losses, it was determined that the performance of carefully scaled centrifugal compressors should be investigated. A program was initiated at NASA Lewis to study the effect of scaling centrifugal compressors to small sizes. In flow sizes where all design parameters could not be directly scaled, test data was obtained to quantify the change in efficiency caused by a variation of each parameter. The data obtained from the NASA Lewis program will be useful in developing models that can be used to predict and minimize the performance loss that is caused by the inability to directly scale all parameters.

A $10-1 \mathrm{~b} / \mathrm{sec}, 8: 1$ pressure ratio, centrifugal compressor was tested at NASA Lewis. This compressor was a direct scale (i.e. all dimensions multiplied by $\sqrt{10 / 25}$ ) of a $25-1 \mathrm{~b} / \mathrm{sec}$ compressor that was designed and tested by Garrett Turbine Engine Company under a program funded by the Air Force Aeronautical Propulsion Laboratory (AFAPL) at Wright Patterson Air Force Base (ref. 4). The $10-1 \mathrm{~b} / \mathrm{sec}$ compressor and test rig were fabricated for NASA Lewis by Garrett (ref. 5).

The $10-1 \mathrm{~b} / \mathrm{sec}$ compressor was intended to be directly scaled down to a flow size of $2 \mathrm{lb} / \mathrm{sec}$, but practical considerations prevented it. The directiy scaled blade thickness and fillet radij would have been less than the minimum 
set by current manufacturing capabilities; so the blade thickness and fillet radii were increased from the directly scaled design. The wall thickness of the $2-1 \mathrm{~b} / \mathrm{sec}$ impeller shroud was also increased. A description of the $2-1 \mathrm{~b} / \mathrm{sec}$ aerodynamic design can be found in reference 6 . To determine the effect of the nonscaled modifications on performance, the $2-1 \mathrm{~b} / \mathrm{sec}$ design was directly scaled back up to a $10-1 \mathrm{~b} / \mathrm{sec}$ flow size, and a second $10-1 \mathrm{~b} / \mathrm{sec}$ compressor was fabri. cated (ref.6) and tested.

The objective of this paper is to present a performance comparison of the two $10-1 \mathrm{~b} / \mathrm{sec}$ compressors. The comparison shows the effect of the modifications to the $2-1 \mathrm{~b} / \mathrm{sec}$ compressor that were scaled up in the design of the second $10-1 \mathrm{~b} / \mathrm{sec}$ compressor. Both compressors were tested over a range of speed, mass flow, Reynolds number and tip clearance. Test results are also presented which show the effect of variations in these parameters on compressor performance.

SYMBOL LIST

b impeller blade height at exit, in.

$\mathrm{CL} \quad$ impeller axial tip clearance at exit, in.

D impeller exit tip diameter, ft

$N \quad$ percent of design equivalent speed

P total stagnation pressure, psia

p static pressure, psia

$\operatorname{Re}$

SM

Reynolds number, $\frac{P_{2} U_{2} D_{2}}{\mu_{1}}$

Surge Margin, $\frac{W \cdot \sqrt{\theta} / \delta / P_{3} / P_{1} \text { ref }}{W \cdot \sqrt{\theta} / \delta / P_{3} / P_{1} \text { surge }}-1 \times 100$

1

total stagnation temperature, ${ }^{\circ} \mathrm{R}$

Tsurface metal temperature of shroud surface at impeller inlet, ${ }^{\circ} R$

$\Delta T_{\text {shroud }}$ temperature difference between shroud surface at inlet and inlet gas temperature, $\left(T_{\text {surface }}-T_{T}\right)$, ${ }^{\circ} R$

$\Delta T_{\text {stage }}$ temperature rise associated with compressor work input, $\left(T_{3}-T_{1}\right),{ }^{\circ} R$

$\mathrm{U} \quad$ impeller tip speed, $\mathrm{ft} / \mathrm{sec}$

W compressor mass flow, $1 \mathrm{bm} / \mathrm{sec}$ 
ratio of compressor inlet total pressure to U.S. standard sea level pressure, $\mathrm{P}_{7} / 14.7$ psia

$n$

$\theta$

$\mu$

$\rho$

$\Omega$

$\omega$ adiabatic temperature rise efficiency, $\frac{\text { ideal }}{\text { actual }} \frac{\text { total enthalpy }}{\text { total enthalpy }}$ rise ratio of compressor inlet total temperature to U.S. standard sea level temperature, $T_{1} / 578.7$

viscosity, $1 \mathrm{bm} / \mathrm{ft} \cdot \mathrm{sec}$

stagnation density at inlet, $1 \mathrm{bm} / \mathrm{ft}^{3}$

mass flow speed parameter, $[(W / N) /(W / N)$ design $]$

diffuser loss coefficient, $\left(P_{3}-P_{2}\right) /\left(P_{2}-P_{2}\right)$

Subscripts

1

station in inlet plenum tank, figure 4

2

station at compressor exit, figure 4

3

station at downstream of diffuser exit, figure 4

\section{COMPRESSOR AERODYNAMIC DESIGN}

The $10-1 \mathrm{~b} / \mathrm{sec}$ compressor with thin blades (ref. 5) is a direct scale (scale factor $=\sqrt{10 / 25}$ ) of the $25-1 \mathrm{~b} / \mathrm{sec}$ AFAPL compressor. This scale factor was applied to the cold coordinates of impeller, diffuser, and shroud contours of the $25-1 \mathrm{~b} / \mathrm{sec}$ compressor. It was also applied to the design tip clearance of the $25-1 \mathrm{~b} / \mathrm{sec}$ stage which resulted in a tip clearance of 0.009 in. in the $10-1 \mathrm{~b} / \mathrm{sec}$ compressor. The aerodynamic design of the $25-1 \mathrm{~b} / \mathrm{sec}$ AFAPL compressor is given in reference 4 .

The 10-1b/sec compressor with thick blades is a direct scale (scale factor $=\sqrt{10 / 2}$ ) of the modified $2-1 \mathrm{~b} / \mathrm{sec}$ compressor. The thick $10-1 \mathrm{~b} / \mathrm{sec}$ impeller and diffuser are shown in figure 1. The modifications that were made to the $2-1 \mathrm{~b} / \mathrm{sec}$ stage mainly involved increases in blade thickness and fillet radii in the impeller and diffuser. A direct scale of the thin $10-1 \mathrm{~b} / \mathrm{sec}$ compressor down to a $2-1 \mathrm{~b} / \mathrm{sec}$ flow size required a minimum blade thickness of 0.007 in. It was determined that the minimum practical thickness for the impeller and diffuser blades was $0.012 \mathrm{in.}$, so $0.005 \mathrm{in}$. was added to all normal thickness values. The impeller throat area and exit blade height of the $2-1 \mathrm{~b} / \mathrm{sec}$ compressor were adjusted to provide the same choke margin and work input as the thin $10-1 \mathrm{~b} / \mathrm{sec}$ compressor. A complete description of the design procedure that was used to adjust the $2-1 \mathrm{~b} / \mathrm{sec}$ compressor is given in reference 6 .

Cross sections of the thick and thin shrouds are shown in figure 2 . The thin compressor was tested with both shrouds, the thick compressor was tested with the thin shroud only. Both shrouds had surface temperature thermocouples located near the impeller inlet. 
The mechanical designs of the thin and thick compressors can be found in references 5 and 6 , respectively. A summary of the design geometry and estimated performance of each compressor is given below.

Thin Thick

$\begin{array}{lrr}\text { Impeller } & & \\ \text { Number of main blades/splitters } & 20 / 20 & 20 / 20 \\ \text { Inlet tip radius, in. } & 4.172 & 4.172 \\ \text { Inlet hub radius, in. } & 2.052 & 2.052 \\ \text { Exit radius, in. } & 6.319 & 6.319 \\ \text { Exit tip width, in. } & 0.403 & 0.417 \\ \text { Design exit tip clearance, in. } & 0.009 & 0.009 \\ & & \\ \text { Oiffuser } & & \\ \text { Number of full vanes/splitter vanes } & 21 / 21 & 21 / 21 \\ \text { Vane inlet radius, in. } & 6.775 & 6.775 \\ \text { Splitter inlet radius, in. } & 7.124 & 7.124 \\ \text { Vane exit radius, in. } & 8.349 & 8.349 \\ \text { Diffuser passage height, in. } & 0.386 & 0.395 \\ \text { Vane L.E. thickness, in. } & 0.013 & 0.027 \\ \text { Vane T.E. thickness, in. } & 0.063 & 0.089 \\ \text { Splitter L.E. thickness, in. } & 0.013 & 0.027 \\ \text { Splitter T.E. thickness, in. } & 0.054 & 0.089 \\ \text { Total Throat Area (sq. in.) } & 5.904 & 5.898 \\ & & \\ \text { Stage } & & \\ \text { Corrected mass flow, ibm/sec } & 70 & 10 \\ \text { Stage total pressure ratio, P3/P1 } & 7.8 & <7.8 \\ \text { Stage total temperature ratio, } 73 / 17 & 1.950 & 1.950 \\ \text { Stage total efficiency, n1-3 } & 0.827 & <0.827 \\ \text { Corrected speed, rpm } & 36366 & 36366 \\ \text { Corrected exit tip speed, ft/sec } & 2007 & 2007\end{array}$

APPARATUS AND PROCEDURE

Compressor Test Facility

The centrifugal compressor test facility was designed for a maximum flow rate of $13 \mathrm{lb} / \mathrm{sec}$, a maximum pressure of $300 \mathrm{psia}$, and a maximum discharge temperature of $800^{\circ} \mathrm{F}$. A schematic of the facility is shown in figure 3 . Atmospheric air enters from a filter house located on the roof of the building. A vaned elbow straightens the flow ahead of the orifice run, which is 16 diameters of straight pipe upstream of the removable orifice plate and 5 diameters downstream. Two inlet valves control the compressor inlet pressure at a predetermined value, ranging from 2 psia to atmospheric (minus line losses). The 16-in. butterfly valve is manually controlled for coarse adjustments and the 6-in. butterfly valve is automatically controlled for fine adjustment.

Another vaned elbow is used downstream of the inlet throttle valve to straighten the flow into a 36 -in. plenum tank. A 5.5 wires/in. screen is located in the plenum to condition the flow before it enters a bellmouth which provides a transition from the plenum to the compressor inlet. 
The compressed air flows into a collector where the flow is controlled by a throttle valve. The throttle valve rotates in a circumferential direction to expose portions of three 2-in. diameter holes located at the collector discharge. The air is discharged back to atmosphere through a pipe which exits through the test cell roof.

The compressor is driven by an electric motor through a two-stage gear box with an overall gear ratio of 11.330:1. The induction motor develops $3000 \mathrm{hp}$ at $3588 \mathrm{rpm}$. Motor speed is determined by a magnetic speed pickup from a 38 tooth gear.

\section{Instrumentation}

Compressor mass flow is determined from the upstream orifice located in the air inlet pipe. The orifice flow is calculated using the standard ASME orifice flow equations for $10-1 / 2$ p pressure taps. Orifice temperature is determined from an average of two chromel-constantan thermocouples located just upstream of the orifice plate. Orifice pressure and delta pressure are each determined from averages of two calibrated pressure transducer readings.

Compressor speed is directly measured by a magnetic speed pickup located over a six tooth sleeve that rotates with the compressor shaft. This measure. ment is compared with the motor and gear box shaft speeds which are multiplied by the appropriate gear ratio to determine compressor speed. A thermocouple reading taken in the plenum tank is used to calculate the corrected speed.

Compressor measurement stations are shown in figure 4 . Inlet conditions were measured in the plenum tank (measurement station 1). Inlet total tempera. ture was measured with two bare wire chromel-constantan thermocouples. Inlet total pressure was obtained from an average of two calibrated pressure transducers connected to pressure taps in the plenum tank. Eight static pressure taps were spaced evenly around the impeller exit tip (measurement station 2).

The compressor exit measurement station 3 was located just downstream of the bend in the exit discharge passage. Total temperature measurements were obtained from eight total temperature rakes which were calibrated for Mach number effects and spaced around the exit passage circumference. Each total temperature rake contained three chromel-alumel elements located at 10, 50, and 90 percent of exit passage height. Exit total pressure measurements at station 4 were obtained from six four-element rakes, located at $8,34,60$, and 86 percent of exit passage height. The exit passage hub and shroud each contained four equally spaced wall statics that were at the same axial location as the total pressure and temperature rakes.

All research pressure readings downstream of the plenum were measured with scanning type valves that use a single calibrated pressure transducer which is accurate to \pm 0.1 percent of full scale. Thermocouples are connected to a floating point reference. Measured temperatures are accurate to $\pm 1{ }^{\circ} R$. The data has been corrected to standard day conditions based on the plenum tank measurements. 
The test rig was equipped with a clearance control mechanism (fig. 4) which allowed the impeller to be translated forward or aft during operation. The impeller to shroud axial clearance was measured using graphite rub probes. A description of the clearance control mechanism is given in reference 5 .

A deflection versus rotational speed curve was determined for each impeller at the start of the test program. A baseline measurement of rub probe length was established with the impeller set at an extreme aft position and rotating at less than $1000 \mathrm{rpm}$. The change in rub probe length was then measured after operation at $60,70,80,90$, and 100 percent of design speed. The probes were measured after operating a mid-flow point for approximately one-half hour and again after a compressor surge at each speed. At 100 percent speed the measurements indicated that the impeller exit tip deflected an additional 0.009 in. during surge.

\section{Test Procedure}

Stage performance data were taken at speeds of $60,70,80,90$, and 100 percent of design speed. Operating clearance was set by adding the design speed mid-flow deflection to the required tip clearance $(0.009 \mathrm{in.})$ and moving the impeller to the proper starting point. The graphite rub probes were measured after each test to verify that the impeller had actually been at the desired axial tip clearance. At speeds below design, the clearance was greater than 0.009 in. because there was less impeller deflection.

At each speed the mass flow was varied from choke to near surge using the compressor exit throttle. Compressor surge was determined by an increase in compressor noise which was accompanied by instability in analog ( $x-y$ recorder) measurements of compressor mass flow and pressure ratio. Because the additional deflection of the impeller at surge was equal to the operating clearance of 0.009 in., the surge point was found only once at design speed with an initial clearance set point of $0.018 \mathrm{in}$.

At each speed the Reynolds number was set by changing the inlet total pressure, which varied the inlet stagnation density. The inlet total pressure and speed were held constant as mass flow was reduced. At design speed the compressor was tested at five Reynolds numbers corresponding to inlet total pressures of $3,6,9,12$, and $14 \mathrm{psia}$. The inlet pressure could not be reduced as far as speeds below 100 percent because the compressor pressure rise at low speed was not high enough to overcome exhaust system losses. At 60 and 70 percent speed, 9 psia was the lowest inlet pressure that could be used. At 80 and 90 percent it was 6 psia.

A test of efficiency change with clearance was conducted on the thin compressor, thin shroud configuration. The peak efficiency point was found for design speed at the design tip clearance of 0.009 in. The clearance control mechanism was then used to increase the tip clearance by $0.001 \mathrm{in}$. and the throttle was adjusted until peak efficiency was found at the new clearance. The procedure was repeated until the impeller to shroud axial clearance was $0.027 \mathrm{in}$. 
The pressure and temperature ratios were determined from arithmetic aver. ages of the total pressures and temperatures at station 3 and measurements in the plenum tank. A polynomial curve fit of gas table properties for air, which accounts for the change in specific heat over a large temperature rise, was used to find the enthalpy rise. Efficiency was determined by comparing the ideal and actual total enthalpy rise.

The measured total temperature at station 3 , the measured static pressure at the impeller exit (station 2), and the orifice mass flow measurement were used to calculate the total pressure at the impeller exit. The calculation procedure was based on continuity and the Euler work equations. The flow area was calculated from the impeller exit tip diameter and the blade height plus clearance at the impeller exit. No aerodynamic blockage was assumed. Impeller efficiency was determined the same was as stage efficiency, except that the total pressure used was the calculated total pressure at the impeller exit.

The diffuser loss coefficient $(\omega)$ is based on the calculated impeller exit total pressure, the measured static pressure at station 2 , and the measured total pressure at station 3 .

\section{RESULTS AND DISCUSSION}

\section{Stage Performance}

The overall performance of each compressor operating with an inlet pressure of 14 psia is presented in figure 5. Total pressure ratio, temperature rise, and adiabatic efficiency based on total conditions are presented as a function of equivalent mass flow for five speeds. The tip clearance was 0.009 inches at design speed. At the design equivalent tip speed of $2007 \mathrm{ft} / \mathrm{sec}$ and the design equivalent mass flow of $101 \mathrm{~b} / \mathrm{sec}$, the thin com. pressor produced a pressure ratio of 7.69 with a total adiabatic efficiency of 0.792 . At the same equivalent speed and mass flow, the thick compressor produced a pressure ratio of 7.64 with a total efficiency of 0.777 . The results presented above are from tests using the thin shroud.

The design speed peak efficiency of both compressors occurred at the design mass flow of $10 \mathrm{lb} / \mathrm{sec}$. The thick compressor provided more energy addition at that flow but did not achieve a corresponding increase in pressure. In figure 5 , the temperature rise of the thin compressor at the design mass flow was 0.98 , compared to 1.00 for the thick compressor. The higher work input of the thick compressor at design flow is probably due to the slight increase in exit blade height that was incorporated in the $2-1 \mathrm{~b} / \mathrm{sec}$ design. This increase was scaled up to $10 \mathrm{lb} / \mathrm{sec}$ along with all other modifications that were made in the $2-1 \mathrm{~b} / \mathrm{sec}$ design. The lack of a corresponding increase in pressure indicates that the thick compressor had higher losses due to the increased blade thickness and fillet radij in the impeller and diffuser.

The thin compressor demonstrated higher performance at all speeds. The efficiency increased with speed from 0.753 at 60 percent to a maximum of 0.798 at 90 percent speed. At design speed the efficiency of thin compressor decreased slightly to 0.792 . This fall off is explained in the next section. 
The efficiency of the thick compressor steadily rises with speed from 0.750 at 60 percent to 0.777 at 100 percent except for a 0.006 drop at 70 percent. The reasons for this drop are not known.

Based on the pressure ratio obtained at the design mass flow of $101 \mathrm{~b} / \mathrm{sec}$, the thin compressor had a design speed surge margin (SM) of 10.5 percent com. pared to 7.7 percent for the thick compressor. The difference in surge margin is primarily due to a difference in the pressure ratio of each compressor at surge. For the thin compressor, the pressure ratio continued to rise as the mass flow was reduced. The pressure ratio and temperature rise of the thick compressor flattened out at 98 percent of design flow and remained fairly constant as the mass flow was further reduced. This pattern suggests that the flow through the thick impeller became more highly separated as flow was reduced.

Both compressors had a choke flow rate of $10.2 \mathrm{lb} / \mathrm{sec}$ at design speed. A mass flow-speed parameter $(\Omega)$ (described by Klassen, Wood, and Schumann, ref. 7) is plotted as a function of speed for the thin and thick compressors in figure 6. A positive slope between two points indicates diffuser controlled flow, a negative slope indicates inducer controlled flow. In figure 6 the slope of each line segment is positive, indicating a diffuser controlled flow up to design speed for both the thick and thin compressors.

\section{Component Performance}

The individual component performances of the thin and thick compressors are presented in figure 7 for the same operating conditions as the stage data that were presented in figure 5. Impeller total pressure, impeller adiabatic efficiency based on total conditions, and diffuser loss coefficient are shown as a function of mass flow for five speeds.

The peak efficiency of the thin impeller increased with speed from 3.876 at 60 percent speed to 0.901 at design speed. The impeller showed almost no increase in efficiency between 90 and 100 percent speed, but the diffuser loss coefficient went from 0.284 to 0.301 . The slight $(0.006)$ decrease that was observed in averall stage efficiency at design speed in figure 5 is thus attributed to the increase in the loss coefficient of the thin diffuser at design speed.

The efficiency of the thick impeller was lower over the speed range and only reached 0.890 at design speed. The minimum loss in the thick diffuser was also higher at all speeds. The data presented in figure 7 show that the nonscaled modifications included in the design of the thick compressor lowered the performance of both the impeller and diffuser.

\section{Effect of Reynolds Number on Performance}

The stage performance of both compressors over a range of Reynolds number is shown in figure 8 . Stage total pressure ratio, total temperature rise, and adiabatic efficiency are presented as a function of design equivalent mass flow for five Reynolds numbers. The data shown were obtained at design speed with 0.009 in. of exit tip clearance. The operating point of interest in obtaining 
this data was the peak efficiency point of each speed line, therefore the surge point was not obtained at every Reynolds number.

As the Reynolds number was reduced the maximum pressure ratio, peak efficiency, and equivalent mass flow where peak efficiency occurred, decreased in both compressors. The same trends were reported in earlier work by Heidelberg, Ball, and Weigel (ref. 8) on a 6-in centrifugal compressor. The explanation given in reference 8 can also be applied to the results presented here.

The reduced equivalent mass flow at peak efficiency is explained in terms of an increase in boundary layer thickness that occurs as the Reynolds number is reduced. The increased boundary layer thickness causes a reduction in the effective flow area in the impeller, which increases the impeller through flow velocity at a given mass flow. If the relative flow angle leaving the impeller is assumed to remain constant, the nigher through flow velocity will cause a reduction in the absolute flow angle leaving the impeller and entering the diffuser. As the flow rate is reduced by closing the compressor exit throttle, the through flow velocity is reduced to the point where the optimum flow angle is once again achieved. However, since the effective impeller flow area has not been changed by closing the throttle, the equivalent mass flow where the optimum flow angle again occurs must be lower.

The increase in through flow velocity should also result in a reduction in compressor work input at the lower Reynolds numbers. As figure 8 shows, the total temperature rise, and therefore the work input of both compressors did decrease with Reynolds number. The reduction in total temperature rise was greater for the thick compressor over nearly the same range of Reynolds number.

The decrease in pressure ratio of the thick compressor was also greater over the same Reynolds number range. However the peak efficiency change in both compressors was about the same over this range; -0.031 and -0.038 for the thin and thick compressors, respectively. The difference is within experimental accuracy, which leads one to conclude that the additional loss in pressure ratio of the thick compressor can probably be attributed to the corresponding loss in work input.

In general, the pressure loss that is caused by a reduction in Reynolds number cannot be attributed to a reduction in work input only. The peak efficiency points from each Reynolds number in figure 8 are cross plotted in figure 9 which shows efficiency loss $(1$ - eff) as a function of Reynolds number. is

A common relation between efficiency loss ( 1 - eff) and Reynolds number

$$
\frac{(1-\text { eff })}{(1-\text { eff })_{\text {ref }}}=\left[\frac{\operatorname{Re}}{(\operatorname{Re})_{\text {ref }}}\right]^{n}
$$

where (1 - eff) ref and (Re) ref are known values of loss and Reynolds number. The exponent represents the rate of efficiency loss with Reynolds number for individual compressors. 
Straight lines have been fitted to the data in figure 9 . The data are plotted on logarithmic scales so that the slope of each line corresponds to a value of the exponent in the equation above. The values obtained for each line are in good agreement between the two compressors. They are -0.0939 and 0.0947 for the thick and thin compressors, respectively. The thick compressor had higher efficiency loss at all Reynolds numbers, which again shows the effect of the increased blade thickness and fillet radii.

\section{Effect of Shroud Thickness on Efficiency}

The stage performance of the thin compressor as influenced by Reynolds number and shroud thickness is shown in figure 10. The dashed line shows the variation in loss with Reynolds number for the thin compressor when tested with the thin (thermally scaled) shroud. It is the same data presented on the dashed line in figure 9. The solid line is the variation of loss with Reynolds number for the thin compressor when tested with the thick (containment) shroud. The efficiency loss is approximately the same for both configurations at Reynolds numbers approaching the design Reynolds number of $1.33 \times 10^{7}$. As the Reynolds number is reduced the configuration with the thick shroud losses efficiency much more rapidly than the one with the thin shroud. The value of the exponent for the thick shroud configuration is -0.1834 , compared to a value of -0.0947 for the thin shroud. Reasons for this shroud thickness effect are discussed next.

The results of temperature measurements from shroud surface thermocouples (see fig. 2) that were located at the impeller inlet on the outside surface of each shroud are shown in figure 11. The parameter along the ordinate of figure 11 is the difference between the average shroud surface temperature and the bulk fluid temperature entering the compressor inlet ( $\Delta T_{\text {shroud }}$ ) which has been nondimensionalized by the overall compressor temperature rise ( $\left.\Delta T_{\text {stage }}\right)$. The overall compressor temperature rise represents the maximum potential driving mechanism for heat transfer. This parameter is presented as a function of Reynolds number for the thin and thick shrouds.

If the same heat transfer coefficient exists between the inner surface of either shroud and the fluid stream at a given Reynolds number, then figure 11 shows the potential for heat transfer from the shroud to the air stream by virtue of the temperature difference. The temperature difference, and therefore the heat transfer, increased as the Reynolds number was reduced with both shrouds. However, the increase in heat transfer with decreasing Reynolds number is much greater for the thick shroud.

Heat transfer from the shroud to the fluid stream will result in lower compressor efficiency. The effect is interheating which works in the opposite direction of stage intercooling and lowers efficiency. The trend of efficiency loss with Reynolds number in figure 10 is very similar to the trend of shroud heat transfer with Reynolds number in figure 11. At high Reynolds numbers the difference in loss between the two shrouds approaches zero. The heat transfer parameters for each shroud also approach the same value as the Reynolds number increases. The similarity in the trends, displayed by the efficiency loss in figure 10 and the heat transfer to the compressor inlet in figure 11 , suggests that stage interheating was the cause of the higher loss when the Reynolds number was reduced with the thick shroud. 
The variation of peak stage efficiency with tip clearance at design speed with ambient inlet pressure is shown in figure 12. The data shown are a com. bination of the data obtained from 0.001 . in. variations in tip clearance, and the peak efficiency points from speed line tests. A linear decrease of about 0.25 points $(0.0025)$ in efficiency for every $?$ percent of blade height increase in tip clearance is shown.

\section{SUMMARY OF RESULTS}

The performance of two $10-1 \mathrm{~b} / \mathrm{sec}$ centrifugal compressors was investigated. The compressors had different blade thickness and fillet radii and were tested over a range of speed, mass flow, Reynolds number, and tip clearance. The effect of shroud thickness on compressor performance was also investigated. The major results of this investigation are as follows:

1. At the design speed of $2007 \mathrm{ft} / \mathrm{sec}$ and the design mass flow of $10 \mathrm{lb} / \mathrm{sec}$ the thin compressor produced a pressure ratio of 7.69 with an adiabatic efficiency of 0.792 . At the same operating conditions the thick compressor produced a pressure ratio of 7.64 with an adiabatic efficiency of 0.777 .

2. Performance calculations for the individual components showed that the lower performance of the thick compressor was due to both lower impeller efficiency and higher diffuser pressure loss.

3. The change in efficiency with Reynolds number was nearly the same for both compressors when tested with the same shroud. The exponent used in the loss versus Reynolds number relation was -0.0939 for the thin compressor and -0.0947 for the thick compressor.

4. Measurements of the shroud surface temperature at the compressor inlet indicated that the reason for the higher loss from the thick shroud was the recirculation of heat to compressor inlet. The heat transfer to the compressor inlet caused a stage interheating effect which lowered performance.

5. The efficiency of the thin compressor decreased about 0.25 points for every 1 percent of blade height increase in tip clearance.

\section{REFERENCES}

1. Wiggins, J.0. and Waltz, G.L., "Some Experiences in the Scaling of the NASA 8-Stage Transonic Axial Flow Compressor," SAE Paper 720711, Sept. 1972.

2. Sawyer, C.W. III, "Evaluation of a Low Aspect Ratio Small Axial Compressor Stage," PWA-FR-8499-VOL-1, Pratt a Whitney Aircraft Group, West Palm Beach, FL, Nov. 1977. (NASA CR-135240).

3. Holman, F.F., Kidwell, J.R., and Ware, T.C., "Small Axial Compressor Technology Program," AIRESEARCH-74-310862-VOL-1, -VOL-2, AiResearch Manufacturing Co., Phoenix, AZ, June 1976. (NASA CR-134827-VOL-1, -VOL-2). 
4. Clarke, R.C., Waterman, W.F., and Palmreuter, F., "Turbine Engine Centrifugal Compressor Technology Program," AIRESEARCH-21-0820(52), AtResearch Manufacturing Co., Phoenix, AZ, Aug. 1978. (A150, AFAPL-TR-78-66, Ava11. NTIS as AD-C016469L).

5. Kenehan, J.G., "Scaled Centrifugal Compressor, Collector and Running Gear Program," GR-21-4269, Garrett Turbine Engine Co., Phoenix, AZ, Oct. 1983. (NASA CR-168167).

6. Cargi11, G. and Linder, C., "Scaled Centrifugal Compressor Program," GARRETT-21-5464, Garrett Turbine Engine Co., Phoenix, AZ, Oct. 1986. (NASA (R-174912).

7. Klassen, H.A., Wood, J.R., and Schumann, L.F., "Experimental Performance of a 16.10-Centimeter-Tip-Diameter Sweptback Centrifugal Compressor Designed for a 6:1 Pressure Ratio," NASA TM X-3552, 1977.

8. Heidelberg, L.J., Ball, C.L., and Weige1, C., "Effect of Reynolds Number On Overal1 Performance of a 6-Inch Radial Bladed Centrifugal Compressor," NASA TN D-5761, 1970. 


\section{ORGMAL PAOE IS \\ OF POOR QUALITY}
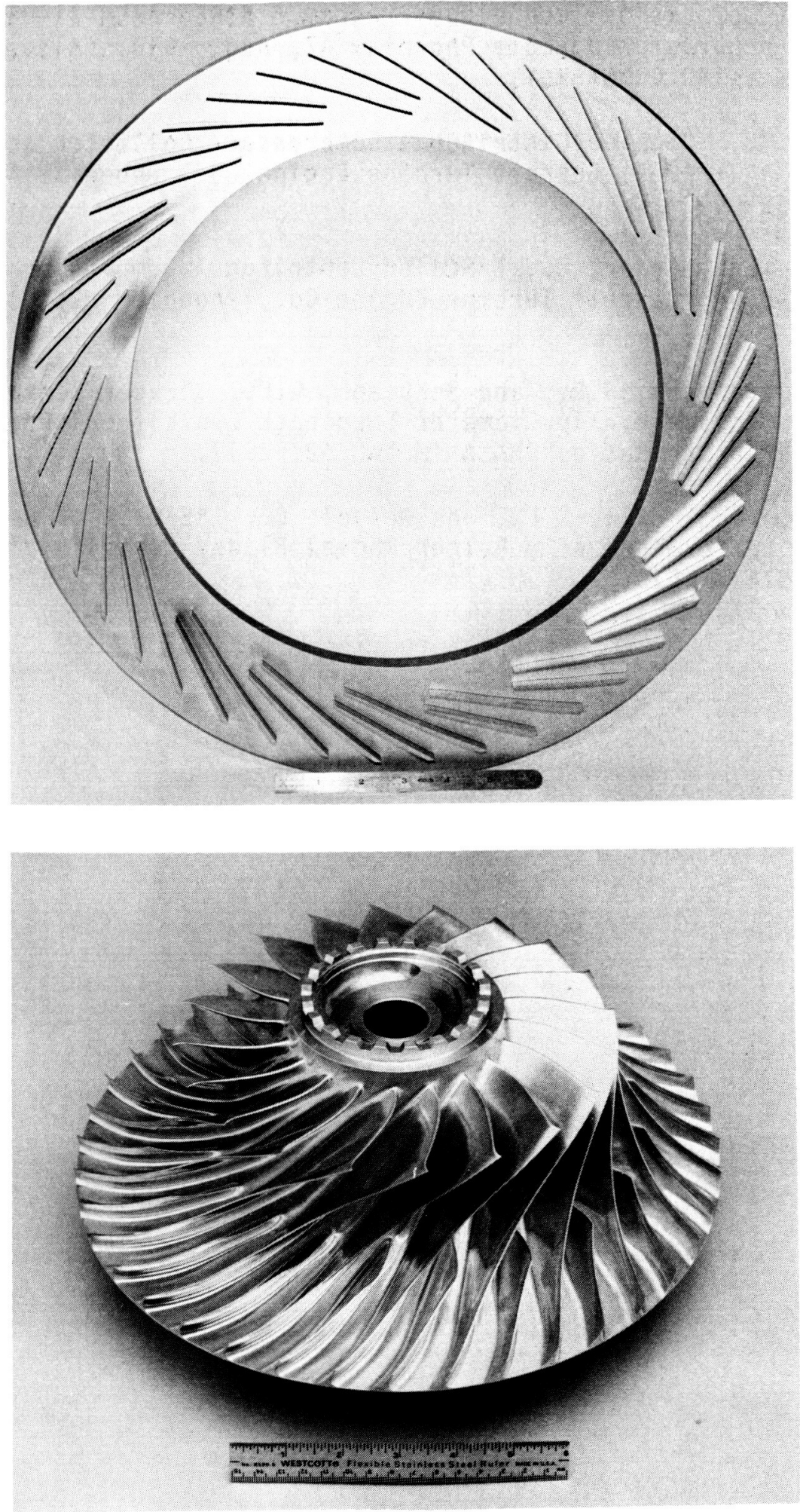

FIGURE 1. - IMPELLER AND DIFFUSER FROM 10 LB/SEC THICK BLADED CENTRIFUGAL COMPRESSOR. 

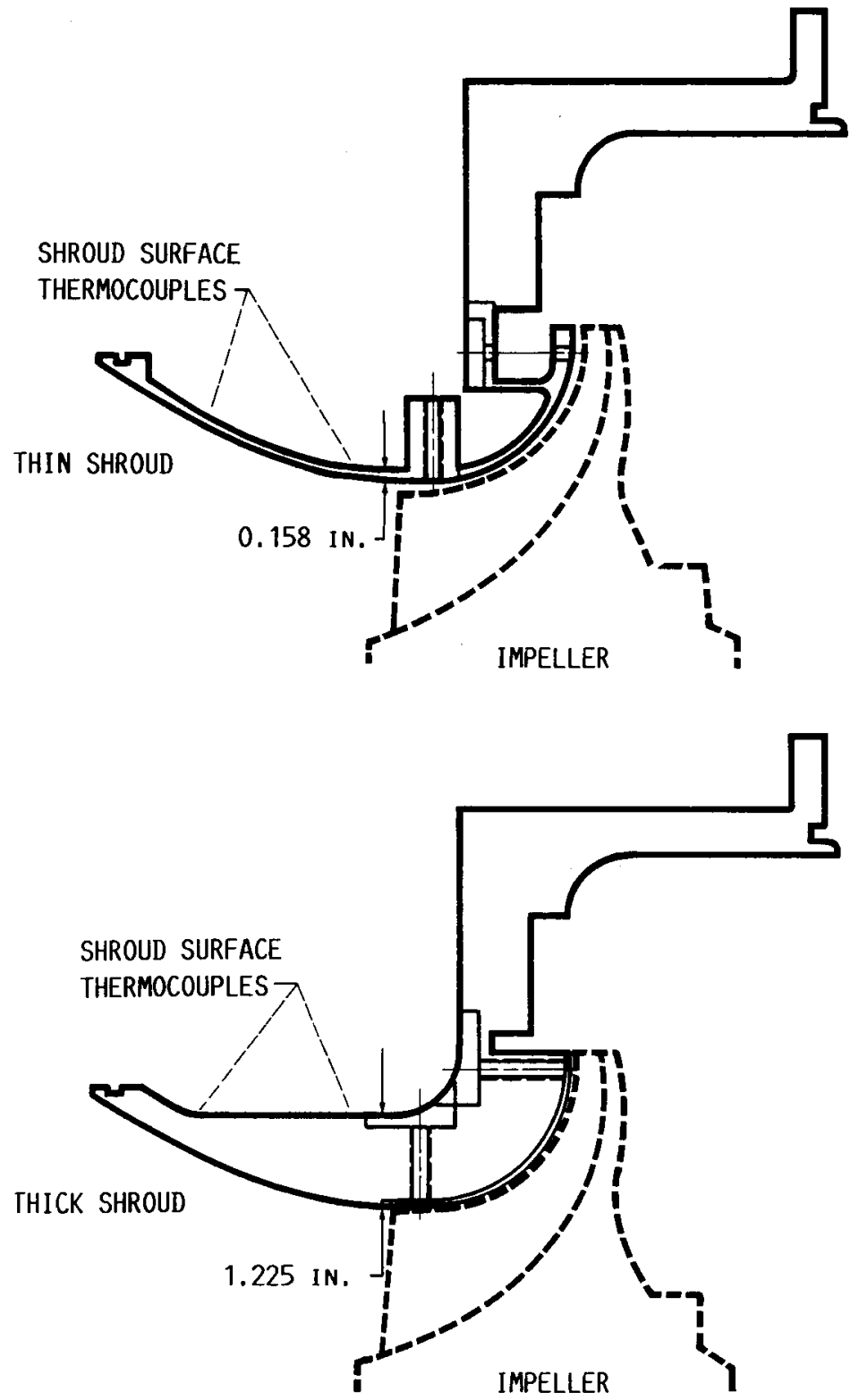

FIGURE 2. - CROSS SECTIONS OF THICK AND THIN COMPRESSOR SHROUDS. 
FACILITY CAPABILITIES

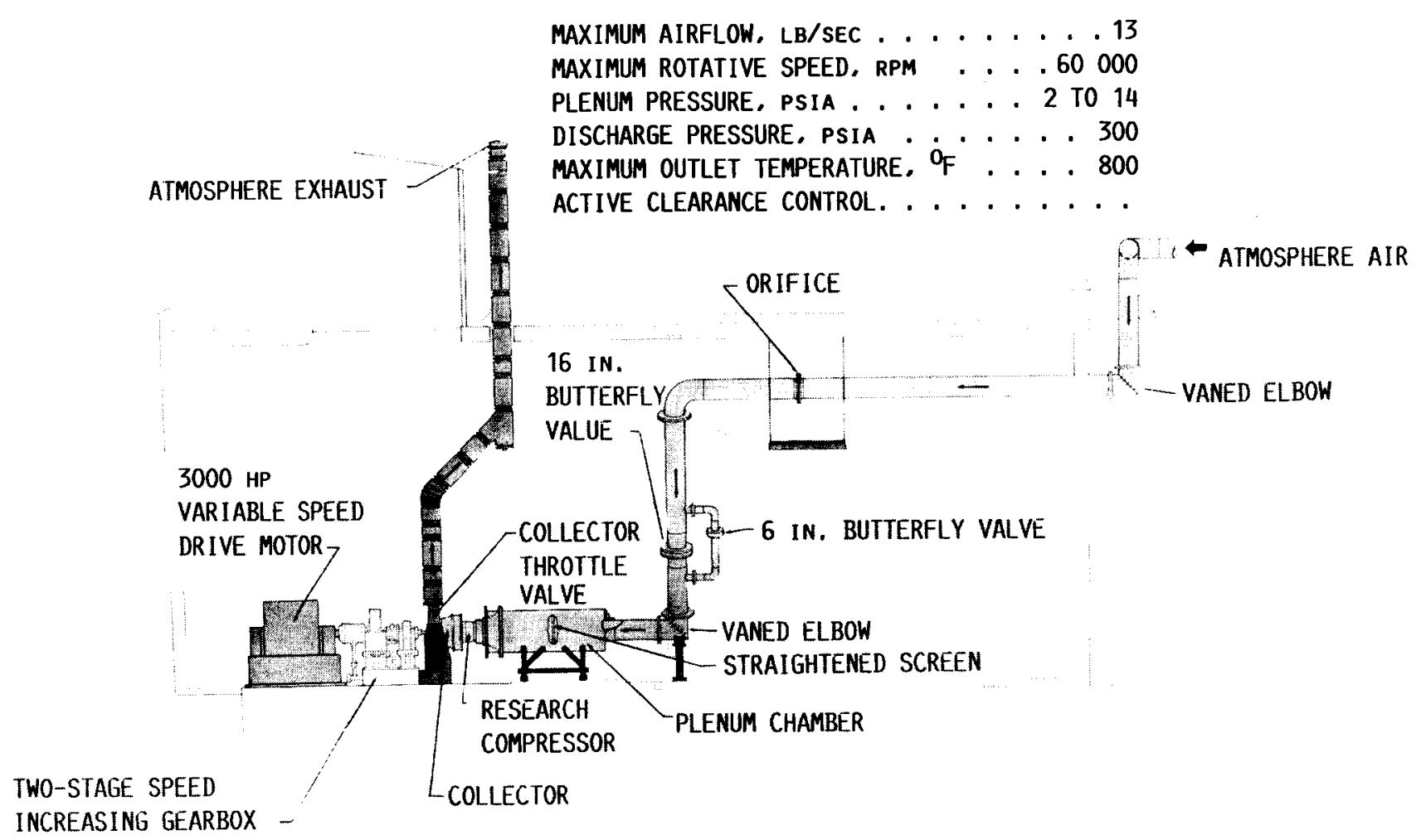

FIGURE 3. - CENTRIFUGAL COMPRESSOR TEST FACILITY. 


\section{ORIGINAL PATEE IS \\ OF POOR QUALITY}

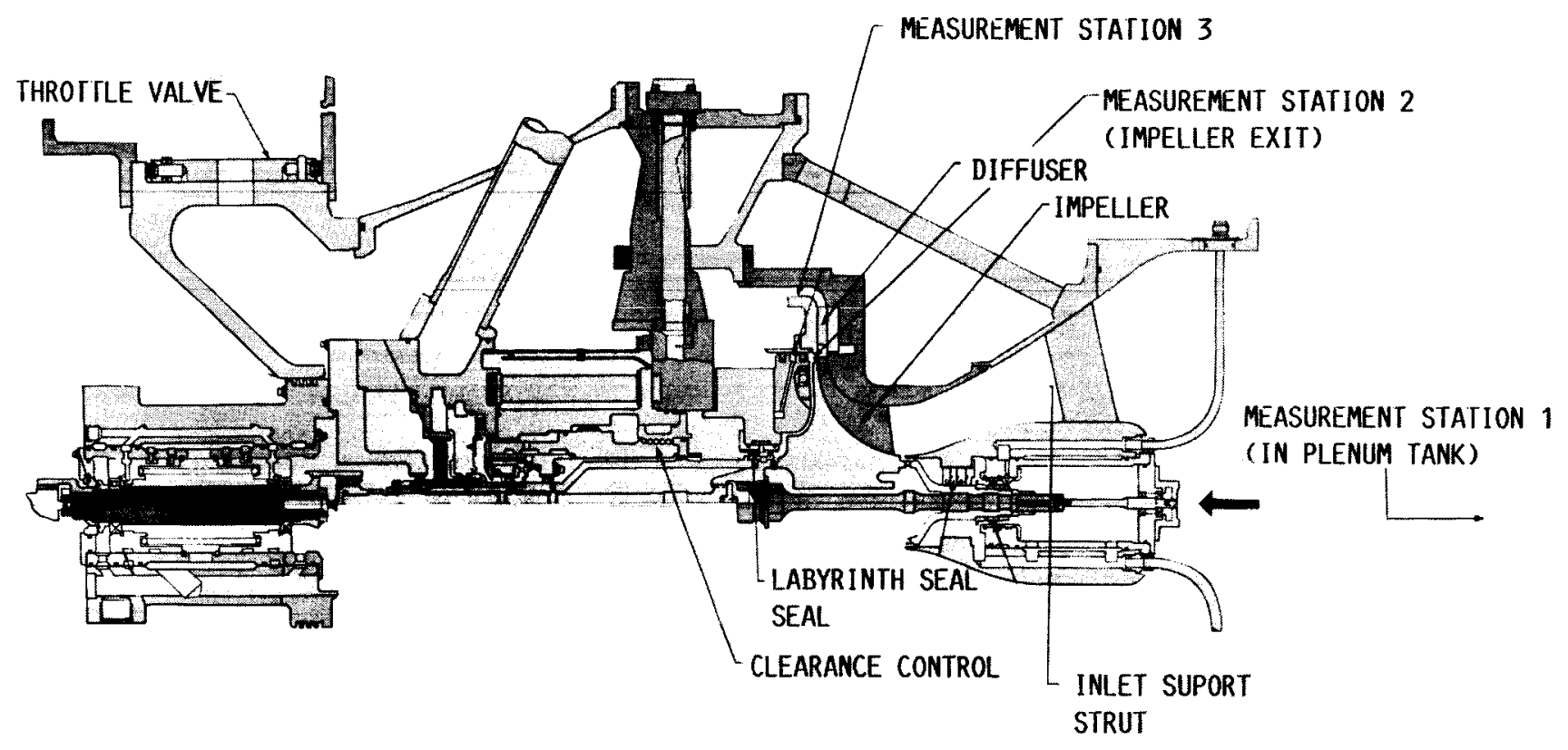

FIGURE 4. - CENTRIFUGAL COMPRESSOR TEST RIG. 


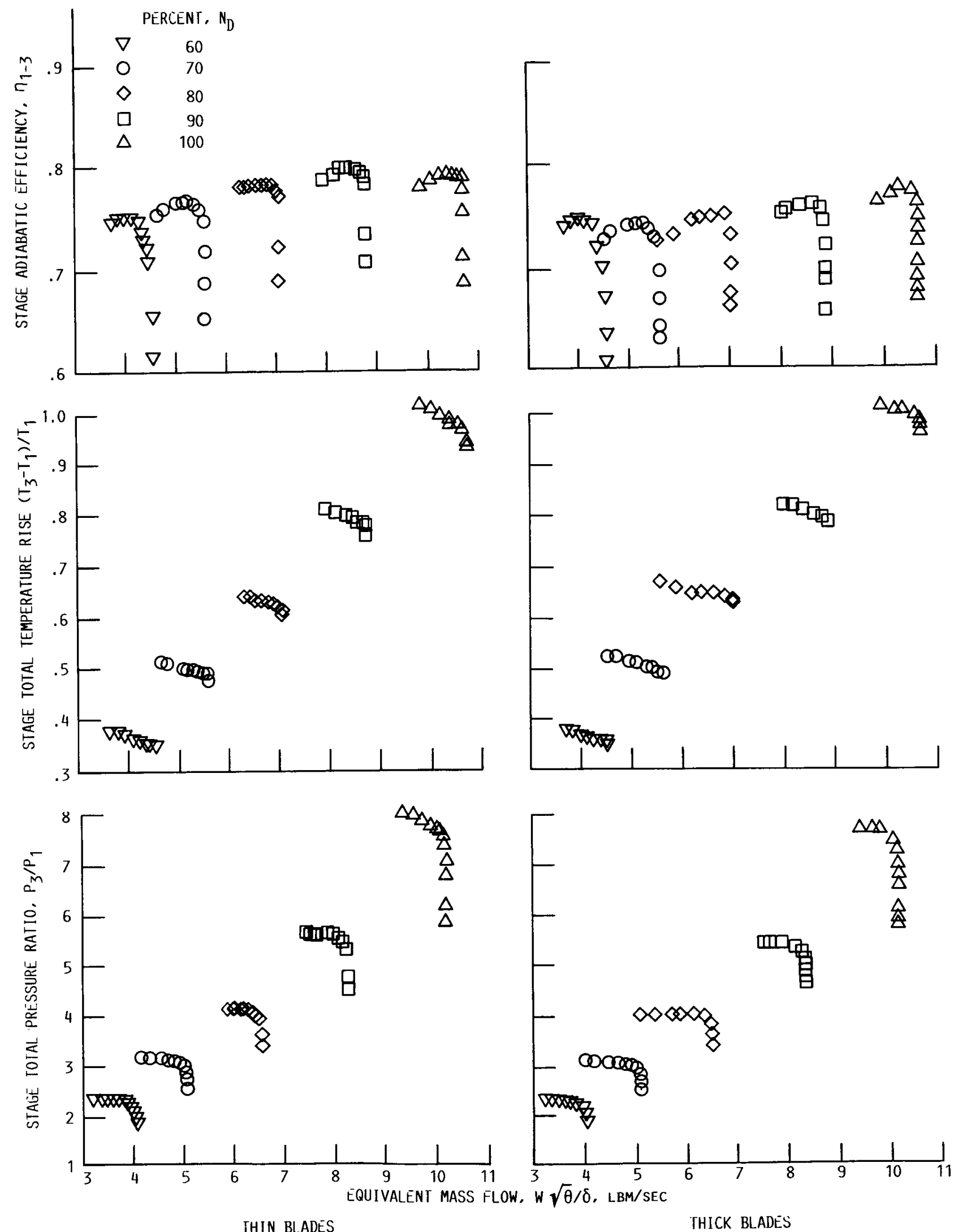

FIGURE 5. - OVERALL PERFORMANCE OF TWO $10 \mathrm{LB} / \mathrm{SEC}$ COMPRESSORS WITH THIN AND THICK BLADES OPERATING OVER A RANGE OF SPEED WITH A THIN SHROUD AND ATMOSPHERIC INLET PRESSURE. 


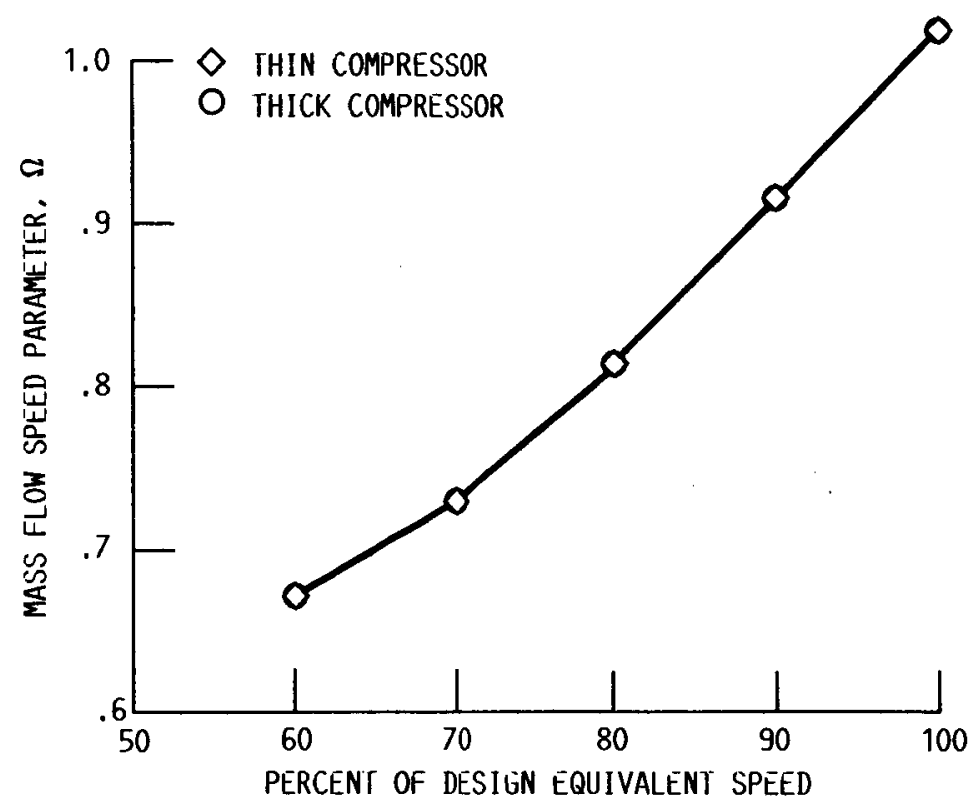

FIGURE 6. - MASS FLOW-SPEED PARAMETER FOR CHOKE FLOW OVER A RANGE OF SPEED FOR THIN AND THICK COMPRESSORS OPERATING WI TH ATMOSPHERÍC INLET PRESSURE. 

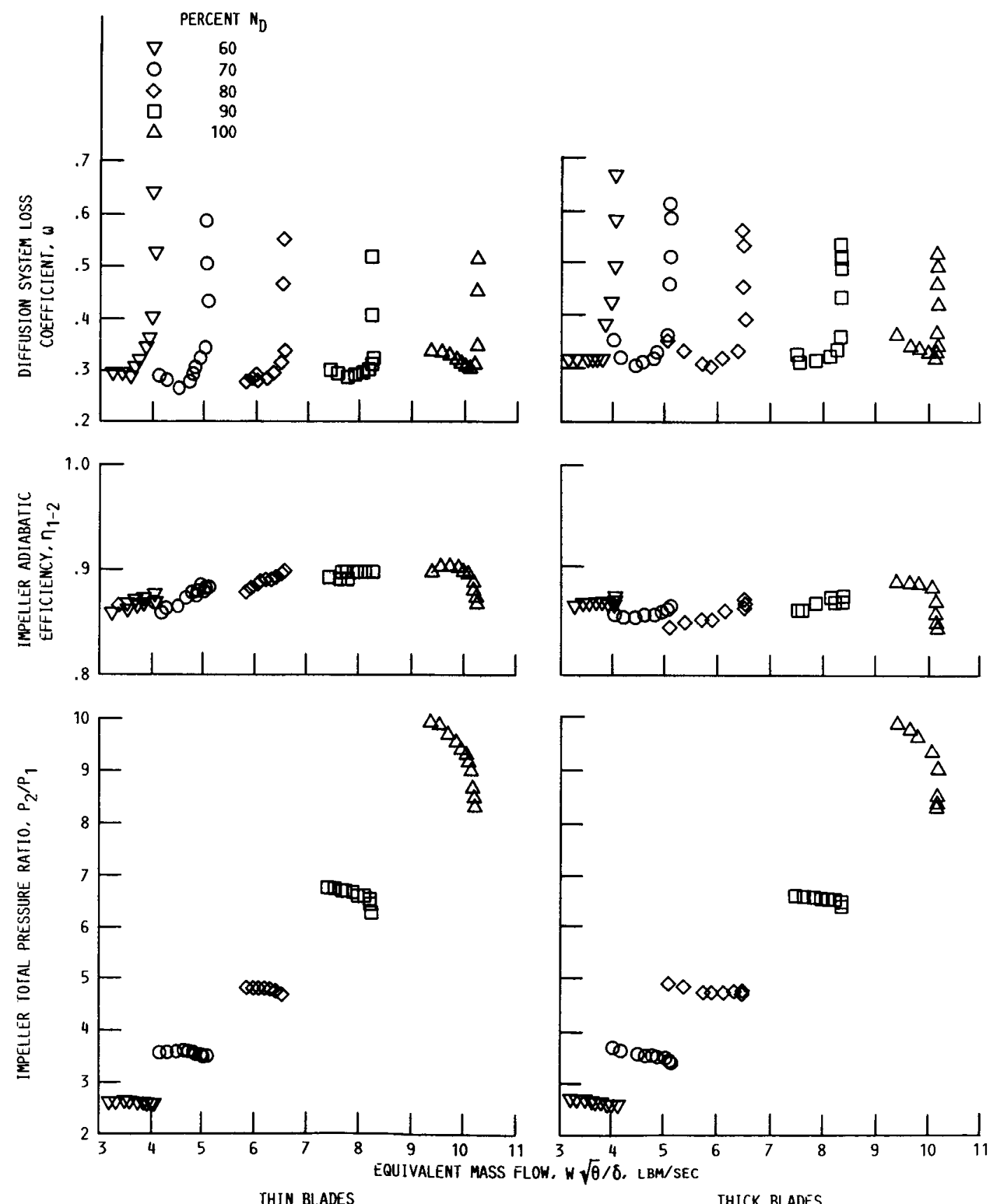

FIgURE 7. - COMPONENT PERformance OF TWO 10 LB/SEC COMPRESSORS WITH THIN AND THICK BLADES OPERATINó OVER A RANGE OF SPEED WITH A THIN SHROUD AND ATMOSPHERIC INLET PRESSURE. 

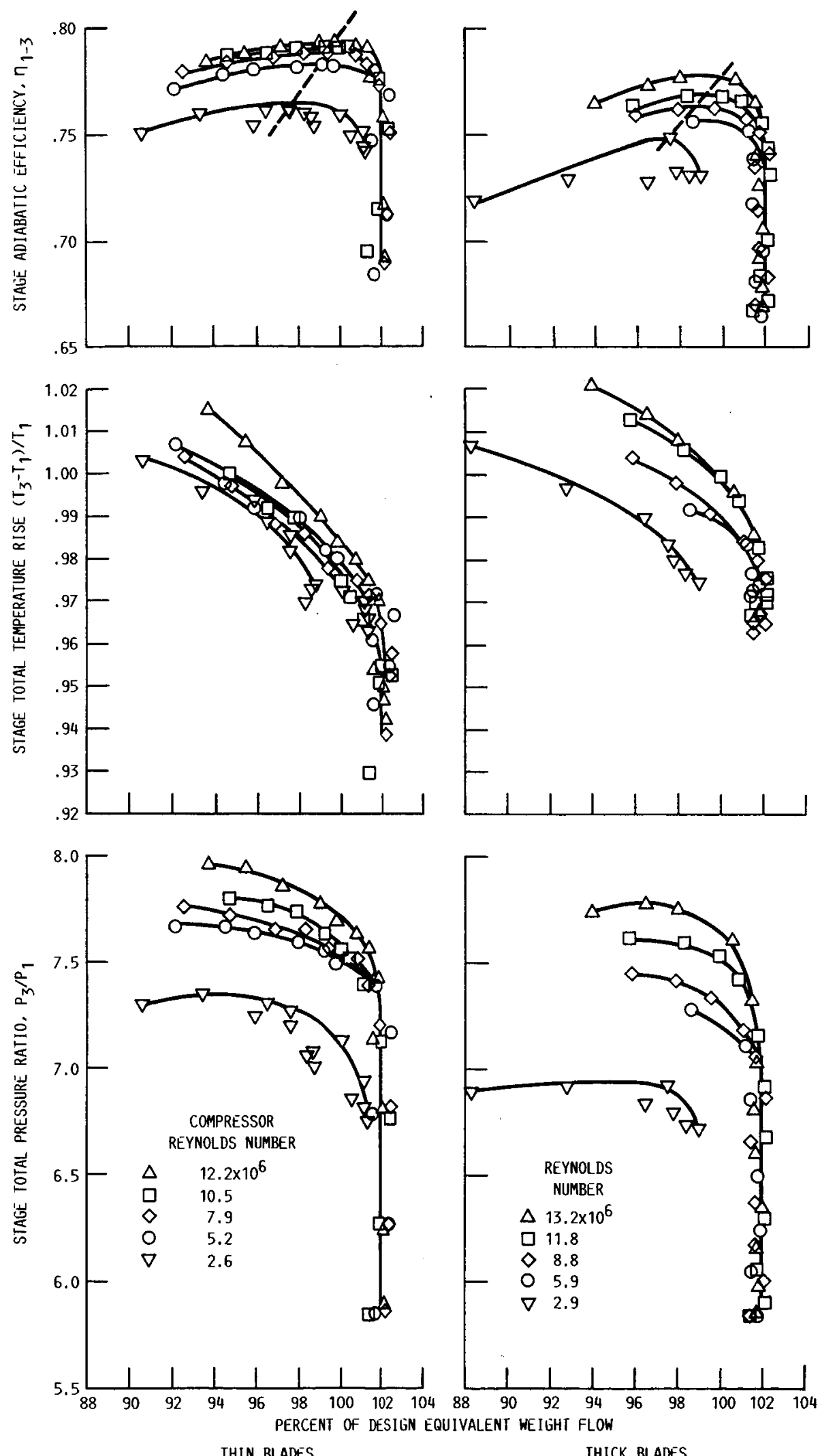

FIGURE 8. - COMPARISON OF COMPRESSOR PERFORMANCE OVER A RANGE OF REYMOLDS NUMBERS AT DESIGN SPEED AND TIP CLEARANCE. 


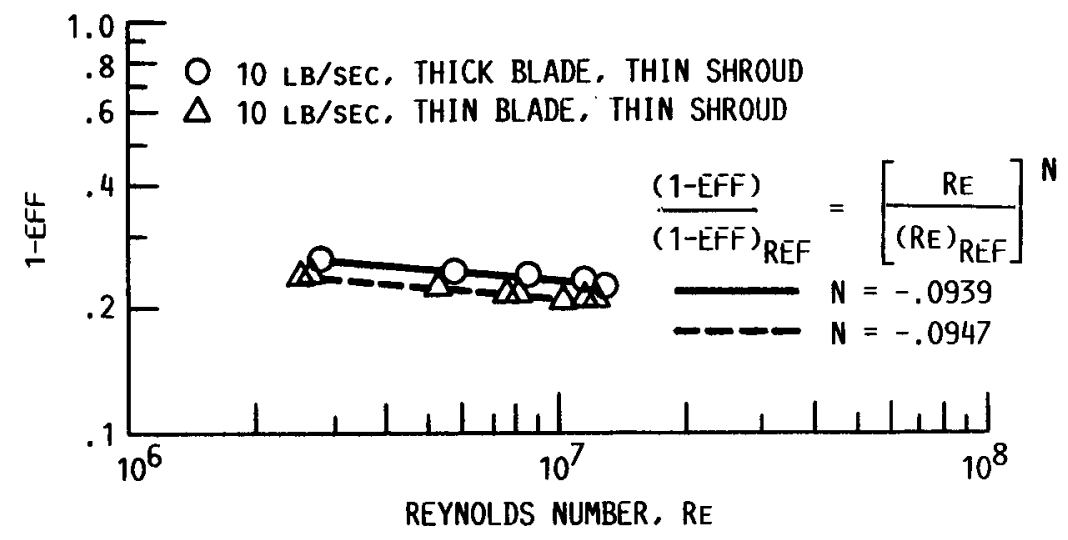

FIGURE 9. - EFFICIENCY LOSS WITH REYNOLDS NUMBER FOR TWO 10 LB/SEC COMPRESSORS WITH THIN AND THICK BLADES TESTED WITH A THIN SHROUD AT 100 PERCENT OF DESIGN SPEED.

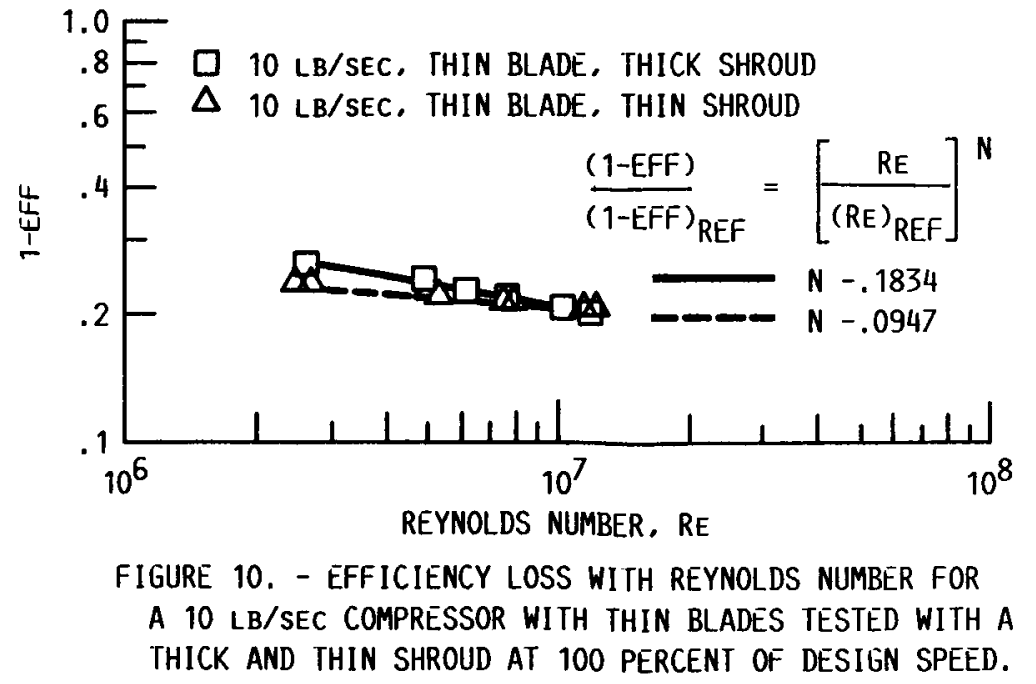




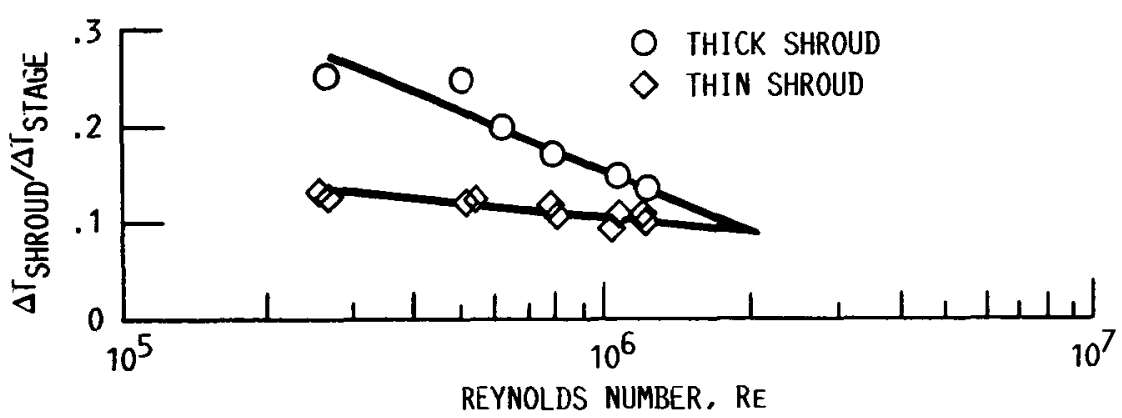

FIGURE 11. - VARIATION OF TEMPERATURE DIFFERENCE BETWEEN SHROUD SURFACE AND INLET BULK FLUID TEMPERATURE AS A PERCENT OF STAGE TOTAL TEMPERATURE RISE FOR 10 LB/SEC COMPRESSOR WITH THIN BLADES OPERATING AT 100 PERCENT OF DESIGN SPEED OVER A RANGE OF REYNOLDS NUMBERS.

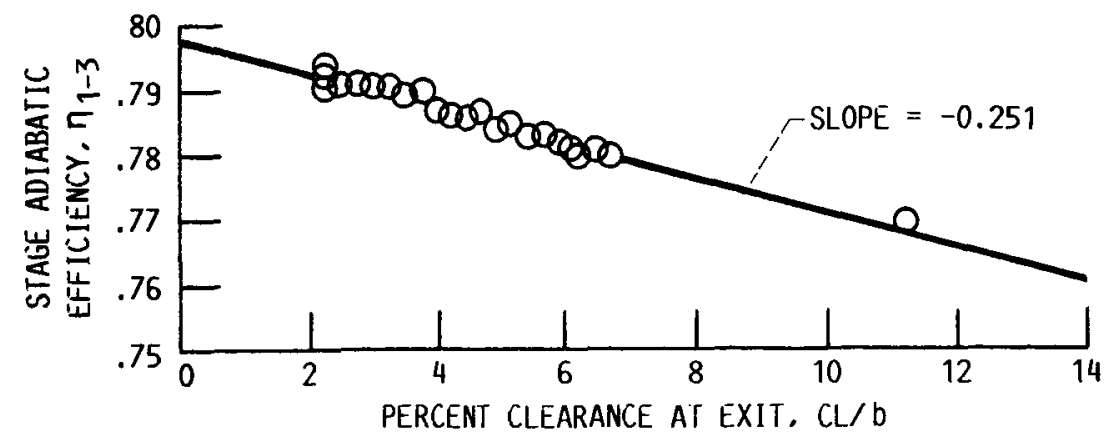

FIGURE 12. - VARIATION IN PEAK STAGE EFFICIENCY WITH EXIT TIP CLEARANCE FOR 10 LB/SEC COMPRESSOR WITH THIN BLADES OPERATING AT 100 PERCENT OF DESIǴN SPEED. 


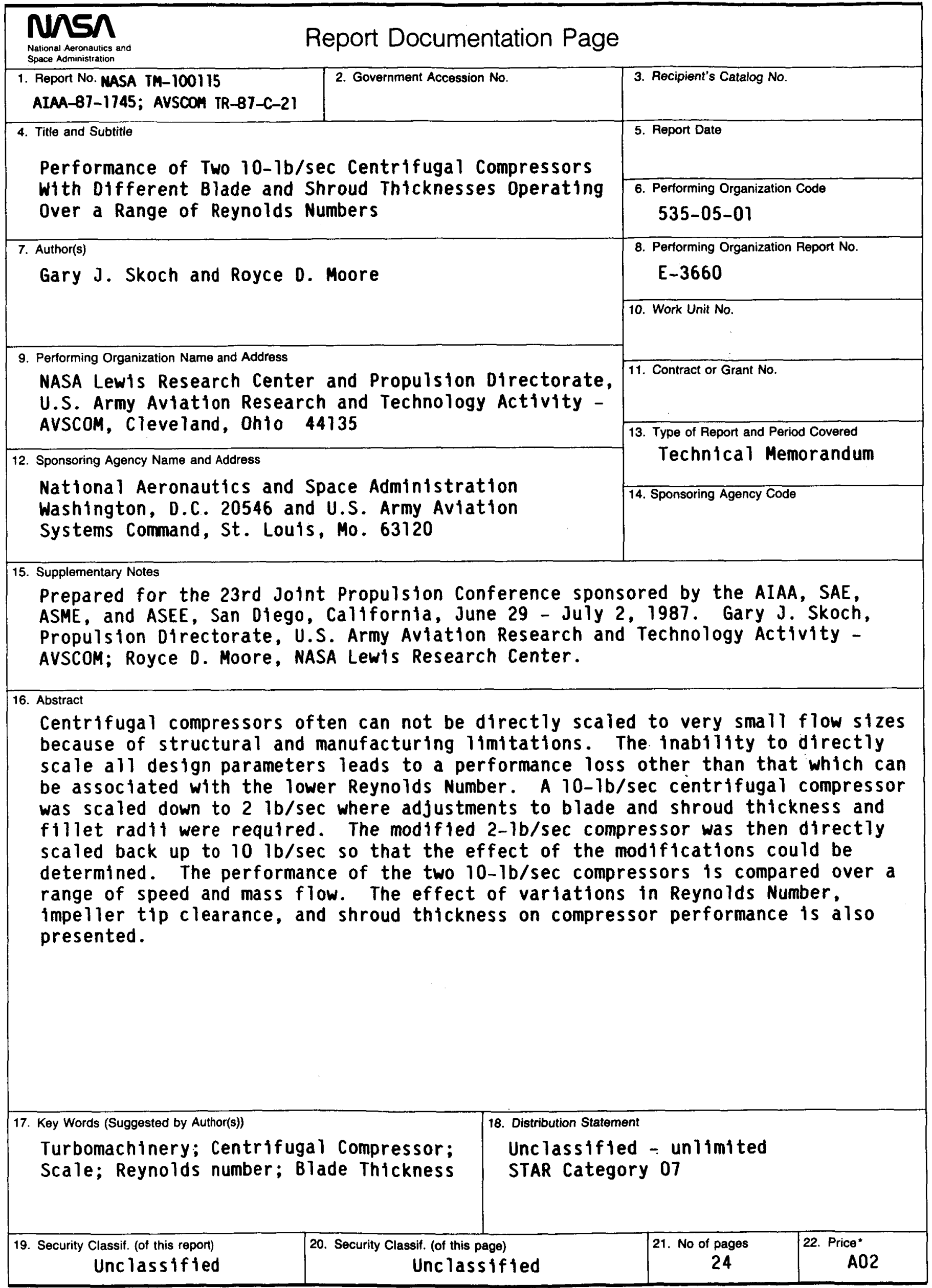

NASA FOAM 1626 OCT $86 \quad$ "For sale by the National Technical Information Service, Springfield, Virginia 22161 